University of Nebraska - Lincoln

DigitalCommons@University of Nebraska - Lincoln

John R. Hardy Papers

Research Papers in Physics and Astronomy

$1-1-1989$

\title{
Theoretical Study of Lattice Instabilities in $\mathrm{YBa}_{2} \mathrm{Cu}_{3} \mathrm{O}_{7}$
}

D. P. Billesbach

University of Nebraska-Lincoln, dbillesbach1@unl.edu

John R. Hardy

University of Nebraska-Lincoln

P. J. Edwardson

L! S. Naval Research Laboratory, Washington, D. C.

Follow this and additional works at: https://digitalcommons.unl.edu/physicshardy

Part of the Physics Commons

Billesbach, D. P.; Hardy, John R.; and Edwardson, P. J., "Theoretical Study of Lattice Instabilities in $\mathrm{YBa}_{2} \mathrm{Cu}_{3} \mathrm{O}_{7}$ (1989). John R. Hardy Papers. 53.

https://digitalcommons.unl.edu/physicshardy/53

This Article is brought to you for free and open access by the Research Papers in Physics and Astronomy at DigitalCommons@University of Nebraska - Lincoln. It has been accepted for inclusion in John R. Hardy Papers by an authorized administrator of DigitalCommons@University of Nebraska - Lincoln. 


\title{
Theoretical study of lattice instabilities in $\mathrm{YBa}_{2} \mathrm{Cu}_{3} \mathrm{O}_{7}$
}

\author{
D. P. Billesbach and J. R. Hardy \\ Department of Physics and Astronomy, University of Nebraska-Lincoln, Lincoln, Nebraska 68588-0111 \\ P. J. Edwardson \\ U. S. Naval Research Laboratory, Washington, D. C. 20375-5000
}

(Received 29 August 1988)

\begin{abstract}
We have performed a molecular dynamics simulation of the $\mathrm{YBa}_{2} \mathrm{Cu}_{3} \mathrm{O}_{7}$ structure under the constraints of the rigid-ion model. These simulations used a variety of charge states for the $\mathrm{Cu}$ ions and the $\mathrm{O}$ ions, and except for one case, the interionic potentials were obtained in an $a b$ initio fashion. The results of these simulations showed that a lattice instability involving the $\mathrm{Cu}-\mathrm{O}$ chains existed. This instability was further investigated and it was shown that simple electronic screening is probably insufficient to stabilize the lattice. An instability of this nature provides a simple explanation of some experimentally observed phenomena.
\end{abstract}

\section{INTRODUCTION}

Since the initial discovery of the high- $T_{c}$ superconducting oxides, ${ }^{1}$ and the rapid climb of $T_{c},{ }^{2}$ there has been a tremendous volume of material written about these compounds. However, in all of this literature there seems to be a distinct lack of work on the theoretical aspects of the crystal structure. In this paper, we present the results of a theoretical simulation of the $\mathrm{YBa}_{2} \mathrm{Cu}_{3} \mathrm{O}_{7}$ structure, with an emphasis on the stability of the lattice.

\section{$\mathrm{YBa}_{2} \mathrm{Cu}_{3} \mathrm{O}_{7} \mathrm{STRUCTURE}$}

The structure of $\mathrm{YBa}_{2} \mathrm{Cu}_{3} \mathrm{O}_{7}$ (hereafter referred to as $\mathrm{Y}-\mathrm{Ba}-\mathrm{Cu}-\mathrm{O}$ ) has been described as perovskitelike. While there are groups of ions in $\mathrm{Y}-\mathrm{Ba}-\mathrm{Cu}-\mathrm{O}$ that resemble arrangements in the perovskite structure, there are major differences between the two. The most important of these is the local potential experienced by each ion. In the

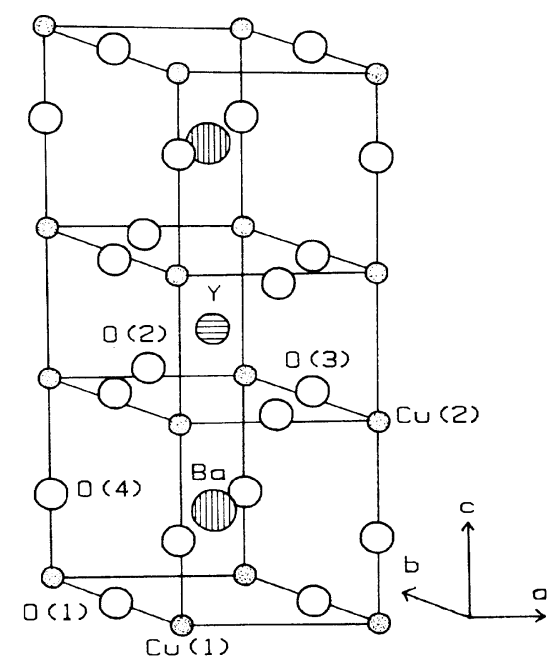

FIG. 1. The $\mathrm{YBa}_{2} \mathrm{Cu}_{3} \mathrm{O}_{7}$ structure (from Ref. 11). perovskite structure, every ion sets at a site with either full cubic symmetry or at a site with very high symmetry. In $\mathrm{Y}-\mathrm{Ba}-\mathrm{Cu}-\mathrm{O}$, this is not the case. Many of the ions are at low-symmetry sites, which as we will show here, contributes to a general destabilization of the lattice.

The superconducting phase of $\mathrm{Y}-\mathrm{Ba}-\mathrm{Cu}-\mathrm{O}$ has orthorhombic symmetry with space group $P m m m{ }^{3}$ As seen in Fig. 1, there are four distinct oxygen sites. The $O(2)$, $O(3)$, and $O(4)$ sites all appear to be at stable potential minima. The $O(1)$ site, however, does not appear to be as stable. We will thus focus our attention on the plane containing the $\mathrm{Cu}(1)-\mathrm{O}(1)$ chains.

\section{TECHNIQUES}

Two main procedures are used in our simulations of the $\mathrm{Y}-\mathrm{Ba}-\mathrm{Cu}-\mathrm{O}$ structure. The first is a static minimization of the total potential energy (Madelung energy plus short-range energy). This allows us to selectively "freeze" the coordinates of certain ions or lattice vectors, or to constrain the simulation sample to a given symmetry, and provides us with a "constrained ground-state structure" at zero temperature. The other procedure is a constantpressure molecular dynamics simulation. ${ }^{4}$ With this program, we are able to find the absolute ground-state structure and to track its evolution as a function of temperature.

\section{MODEL}

As is the case with any theoretical investigation, an appropriate model of the system is required. In this simulation study, we chose the rigid-ion approximation as the descriptor of the interionic potentials. The short-range pair potentials were calculated using the electron gas model developed by Gordon and Kim. ${ }^{5}$ The electronic charge densities were taken from the tables of Clementi and Roetti $^{6}$ or were determined using the program of Liberman, Cromer, and $\mathrm{Waber}^{7}$, with the $\mathrm{O}^{2}-$ ion stabilized by a Watson sphere of charge $2+$ and inner potential of 0.75 a.u. Using this method, the short-range poten- 
tial was calculated at a number of discrete points. To allow the use of analytic derivatives (as opposed to numerical ones) in our static relaxation and molecular dynamics programs, the discrete potentials were fitted to an analytic function. This potential function consisted of three distinct regions; the core region (which is never actually sampled in our simulations), the intermediate region, and the tail. The core potential is represented by

$$
U(r)=A+B r^{-6},
$$

where $r \leq r_{c}$; the intermediate potential is represented by

$$
U(r)=\exp (-\alpha r) \sum_{n=0}^{6} C_{n} r^{m+n},
$$

where $r_{c}<r<r_{t}$; and the tail region is represented by

$$
U(r)=C \exp \left(-\beta r^{2}\right),
$$

where $r \geq r_{t}$. The constants in these functions were determined by requiring continuity of the potential and its derivatives where the different regions join. The longrange or Madelung energy was calculated using a standard Ewald summation.

This model is perhaps the simplest parameter-free approach to the problem at hand. In many respects, the rigid-ion model is in fact inappropriate for the study of conductors (most notably in its lack of free electronic contributions). The model has, however, been successfully applied to systems such as $\mathrm{RbCaF}_{3},{ }^{8} \mathrm{CsCaF}_{3},{ }^{9}$ and $\mathrm{Rb}_{2} \mathrm{ZnCl}_{4}{ }^{10}$ We therefore expect that this simple model will provide us with some insights to the gross structural behavior of $\mathrm{Y}-\mathrm{Ba}-\mathrm{Cu}-\mathrm{O}$.

\section{SIMULATION RESULTS}

The first step of our simulation was to examine the Pmmm symmetry phase. This was done using the static relaxation program. Our starting structure used experimental ionic positions obtained from neutron scattering. ${ }^{11}$ The structural parameters were than varied (within the Pmmm symmetry constraints) to minimize the potential energy of the lattice. To begin, we must establish the charge state of each ion under the constraint that the lattice as a whole remains electrically neutral. Evidence indicates that some of the copper ions are in the $3+$ charge state. $^{12}$ A logical placement of these charge states would be on the $\mathrm{Cu}(1)$ sites, while the $\mathrm{Cu}(2)$ ions would carry a charge of $2+$. The other ions were assigned fixed integer charges: $3+$ for $\mathrm{Y}, 2+$ for $\mathrm{Ba}$, and $2-$ for the oxygen ions. This would maintain charge neutrality within a unit cell, but it also implies an ordering of the triply oxidized copper ions. It has been suggested however, that the $\mathrm{Cu}^{3+}$ ions are not restricted to the $\mathrm{Cu}(1)$ sites, but are more randomly distributed in the cell. ${ }^{13}$ Because of the relatively small size of the simulation sample, this disorder was approximated by assigning a charge of $\frac{7}{3}+$ to all of the $\mathrm{Cu}$ ions. Other evidence ${ }^{14,15}$ seems to indicate that there are no $\mathrm{Cu}^{3+}$ ions, only $\mathrm{Cu}^{2+}$ ions in $\mathrm{Y}-\mathrm{Ba}-\mathrm{Cu}-\mathrm{O}$. To investigate this possibility, a simulation was done with all $\mathrm{Cu}^{2+}$ ions and all $\mathrm{O}^{13 / 7-}$ ions.

The relaxations were performed on samples that consisted of a single unit cell (13 ions or one formula group). The results of the static relaxations are summarized in Table I. The calculations for all three charge states resulted in lattice parameters that were too large. This is an indication that at least one of the interionic potentials (probably the $\mathrm{Cu}-\mathrm{O}$ ) was too hard. It was found that a $40 \%$ reduction of the $\mathrm{Cu}-\mathrm{O}$ potential (for the $\mathrm{Cu}^{7 / 3+}$ charge state) resulted in lattice parameters that were closer to the experimental ones, as can be seen in the table. Although this scaling of the short-range potential gave a somewhat better static simulation, it did compromise the $a b$ initio character of the calculation. We did note, however, that even in the worst of these four cases, the lattice constants were well within $10 \%$ of the experimental values. This indicated that the bonding in $\mathrm{Y}-\mathrm{Ba}-\mathrm{Cu}-\mathrm{O}$ quite likely is mostly ionic in nature.

Using these relaxed Pmmm symmetry cells as the starting points for the molecular dynamics (MD) simulations, we first doubled the cells in all three crystallographic directions. This created simulation samples consisting of eight unit cells (104 ions). The MD simulations were allowed to dwell for $\frac{1}{4}$ psec (50 time steps) at each temperature. We performed MD simulations on the sample cells using the four sets of conditions listed above. This gave us an indicator of the sensitivity of our sample to the $\mathrm{Cu}(1)$ charge state and to the size of the $\mathrm{Cu}-\mathrm{O}$ short-range potential. Upon examination, the three simulations yielded almost identical results in the gross features of the lattice, especially in the $\mathrm{Cu}(1)-\mathrm{O}(1)$ plane. Figures 2 and 3 summarize these results. The figures are sections of the sample cell, cut perpendicular to the $c$ axis and show a plane containing the $\mathrm{Cu}(1)-\mathrm{O}(1)$ chains, and a plane containing the base of one of the half-octahedra $[\mathrm{O}(2)-\mathrm{Cu}(2)-\mathrm{O}(3)]$. Figures 2 and 3 are from the simulation with the $\mathrm{Cu}(1)$

TABLE I. Results of the static relaxations for (1) $\mathrm{Cu}(1)=3+$ and $\mathrm{Cu}(2)=2+$, (2) $\mathrm{Cu}(1)$ and $\mathrm{Cu}(2)=\frac{7}{3}+,(3) \mathrm{Cu}(1)$ and $\mathrm{Cu}(2)=\frac{7}{3}+$ with the $\mathrm{Cu}-\mathrm{O}$ short-range potential reduced by $40 \%$, and (4) $\mathrm{Cu}(1)$ and $\mathrm{Cu}(2)=2+$ and $\mathrm{O}=\frac{13}{7}-$.

\begin{tabular}{lccccc}
\hline \hline & $\begin{array}{c}\mathrm{Cu}(1)^{3+} \\
\text { and } \mathrm{Cu}(2)^{2+}\end{array}$ & $\mathrm{Cu}^{7 / 3+}$ & $\begin{array}{c}\mathrm{Cu}^{7 / 3+} \\
(\text { scaled 40\%) }\end{array}$ & $\mathrm{Cu}^{2+}$ and $\mathrm{O}^{13 / 7-}$ & Expt. (Ref. 11) \\
\hline$a(\AA)$ & 4.0295 & 3.8503 & 3.6679 & 3.9440 & 3.8187 \\
$b(\AA)$ & 4.0877 & 4.1639 & 3.9239 & 4.2496 & 3.8833 \\
$c(\AA)$ & 12.0081 & 12.0670 & 11.3863 & 12.4987 & 11.6687 \\
$b / a$ & 1.01444 & 1.08145 & 1.06668 & 1.07748 & 1.01692 \\
\hline \hline
\end{tabular}



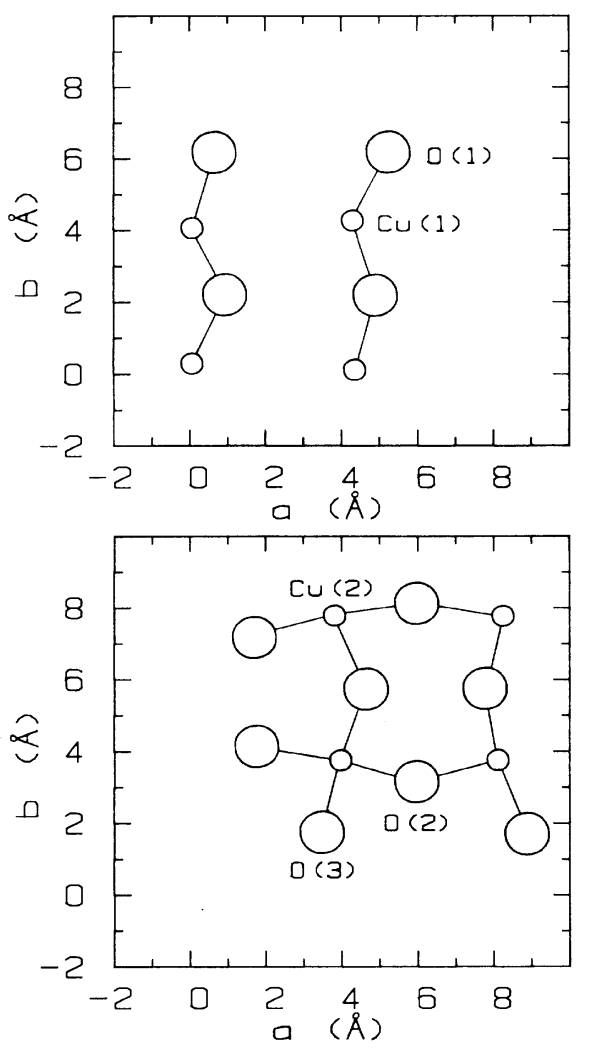

FIG. 2. $a-b$ sections from the MD simulation with $\mathrm{Cu}(1)^{3+}$, $\mathrm{Cu}(2)^{2+}$, and $\mathrm{O}^{2-}$, showing the $\mathrm{Cu}(1)-\mathrm{O}(1)$ chains and the $\mathrm{O}(2)-\mathrm{Cu}(2)-\mathrm{O}(3)$ plane. $T=0 \mathrm{~K}$.

ions in the $3+$ charge state and the $\mathrm{Cu}(2)$ ions in the $2+$ charge state and are for temperatures 0 and $1550 \mathrm{~K}$, respectively. Two features are immediately evident: one, the basal planes of the octahedra $[\mathrm{O}(2)-\mathrm{Cu}(2)-\mathrm{O}(3)]$ have rotated and more importantly, the normally straight $\mathrm{Cu}(1)-\mathrm{O}(1)$ chains have distorted to a zigzag chain. Alternatively, we could say that the $O(1)$ sublattice has shifted coherently along the $a$ axis. As the temperature went up in this simulation, the rotation of the basal plane grew smaller. However, the $\mathrm{O}(1)$ sublattice distortion did not change appreciably with temperature. The simulation where all of the $\mathrm{Cu}$ ions were in the $\frac{7}{3}+$ charge state and the full $\mathrm{Cu}-\mathrm{O}$ potential was used showed essentially the same features, especially in the $\mathrm{Cu}(1)-\mathrm{O}(1)$ plane. The third simulation where all of the $\mathrm{Cu}$ ions were in the $\frac{7}{3}+$ charge state, but the $\mathrm{Cu}-\mathrm{O}$ short-range potential was reduced by $40 \%$, differs from the first two only in the lack of rotation of the $\mathrm{O}(2)-\mathrm{Cu}(2)-\mathrm{O}(3)$ basal plane. Finally, the last simulation with $\mathrm{Cu}^{2+}$ ions and $\mathrm{O}^{13 / 7-}$ ions also showed the same $O(1)$ sublattice distortion as the other three. The strong $\mathrm{O}(1)$ sublattice distortion was present at all temperatures, and in all simulations.

The $O(1)$ sublattice distortion did not disappear at high temperatures in any of the simulations as might be expected. In fact, as the simulation temperature rose, the crystal was always observed to break apart before the $O(1)$ ions
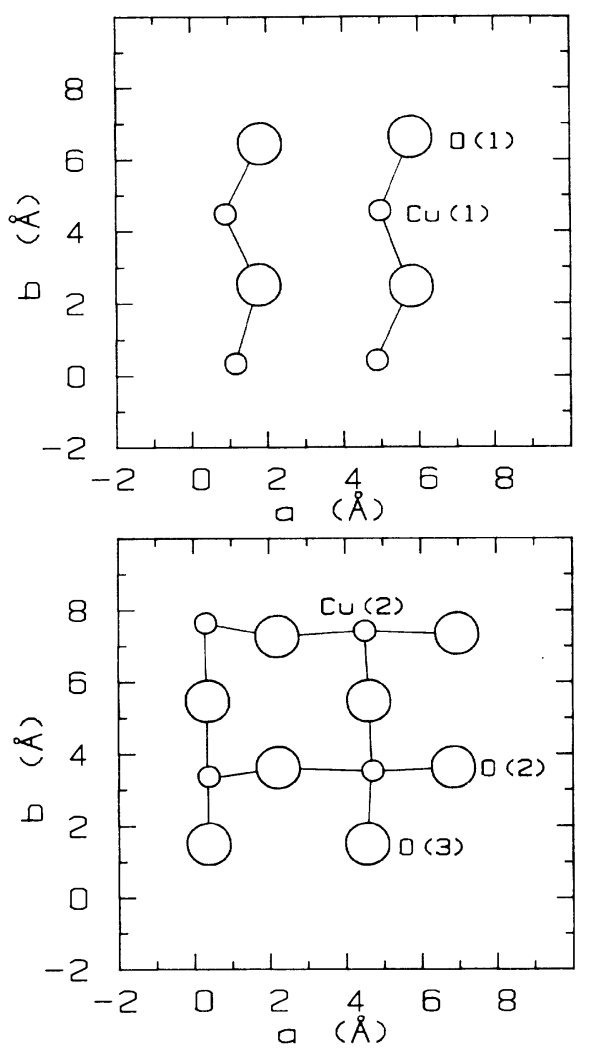

FIG. 3. $a-b$ sections from the MD simulation with $\mathrm{Cu}(1)^{3+}$, $\mathrm{Cu}(2)^{2+}$, and $\mathrm{O}^{2-}$, showing the $\mathrm{Cu}(1)-\mathrm{O}(1)$ chains and the $\mathrm{O}(2)-\mathrm{Cu}(2)-\mathrm{O}(3)$ plane. $T=1550 \mathrm{~K}$.

would move back to their Pmmm sites. This is indicative of a very strong instability in the Pmmm phase.

\section{NATURE OF THE INSTABILITY}

Within the boundaries of the rigid-ion model, the experimental $\mathrm{Y}-\mathrm{Ba}-\mathrm{Cu}-\mathrm{O}$ structure is obviously not stable. In the previous section the instability was shown to mainly involve the $\mathrm{Cu}(1)-\mathrm{O}(1)$ chains. Close inspection of Fig. 1 suggests that while the $O(2)$ and $O(3)$ ions sit at stable sites, the $\mathrm{O}(1)$ ions do not. The lack of adjacent oxygen ions in the $a$ direction [akin to the $\mathrm{O}(2)$ sites] removes a very important stabilizing Coulomb force. This then allows the $\mathrm{Ba}$ ions to initially pull the $\mathrm{O}(1)$ ions in the $a$ direction where the destabilizing Coulomb force is further augmented by the $\mathrm{O}(4)$ ions. Figure 4 shows the Coulomb potential energy seen by the $\mathrm{O}(1)$ ion as a function of the sublattice displacement. This clearly shows the very deep potential well that the $\mathrm{O}(1)$ ions fall into.

Obviously, since this structural distortion is not observed experimentally, it points to a deficiency in our model. Given the fact that in the $\mathrm{Pmmm}$ phase $\mathrm{Y}-\mathrm{Ba}-\mathrm{Cu}-\mathrm{O}$ is metallic, the most obvious feature missing from the rigidion model is the inclusion of free-electron effects. The simplest treatment of this deficiency is to calculate the screening effect that the electrons have on the ions. Using 


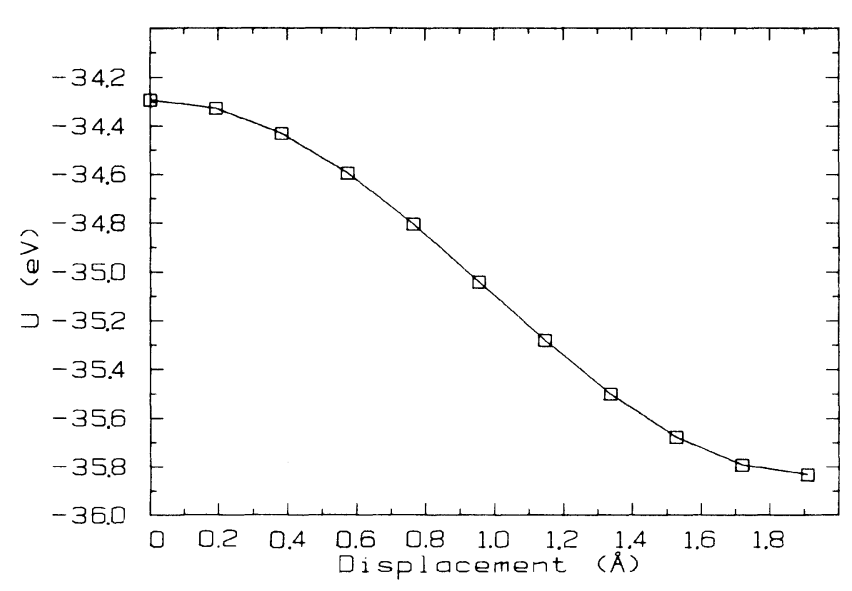

FIG. 4. Coulomb potential energy of the $O(1)$ ions as a function of displacement in the $a$ direction.

experimental data for the electron density in $\mathrm{Y}-\mathrm{Ba}-\mathrm{Cu}-\mathrm{O}$ (Ref. 16) we calculate a Thomas-Fermi screening length of $1.35 \AA$. In the presence of the screening electrons, the ions will no longer see a $1 / r$ Coulombic potential; rather they will see a Yukawa potential of the form

$$
U(r)=(q / r) \exp \left(-r / l_{T-F}\right) .
$$

Unlike the bare Coulomb potential, this screened potential will converge and the mathematical trick of Ewald summation is no longer needed. Figure 5 shows the potential energy for the $O(1)$ ions in the screened lattice as a function of displacement along the $a$ direction. This potential was generated from the contributions of the 230 nearest neighbors. Close examination of Fig. 5 shows that the position away from the $a$ axis is slightly more stable than the position on the $a$ axis (the $1 e$ symmetry site). One trend observed as more and more neighbors were included in this calculation was that the $1 e$ site (on the $a$ axis) became more and more unstable. To check the value of the screening length, it was calculated for free charge densities that differed from the experimental ones by plus and minus two orders of magnitude. The resulting screening lengths gave qualitatively similar potential wells. Obviously, screening will not stabilize the lattice.

While screening should play a large role in the overall structural properties of $\mathrm{Y}-\mathrm{Ba}-\mathrm{Cu}-\mathrm{O}$, the preceding demonstrates that screening alone cannot stabilize the lattice. Thus, it seems reasonable to associate this theoretical instability with the unique brand of superconductivity seen in this compound. $\mathrm{Y}-\mathrm{Ba}-\mathrm{Cu}-\mathrm{O}$ is known to exist in the Pmmm symmetry structure. This suggests that the theoretical instability found in the simulations may be manifested in the real crystal as a double-well potential that spans the le symmetry site in the $a$ direction. This

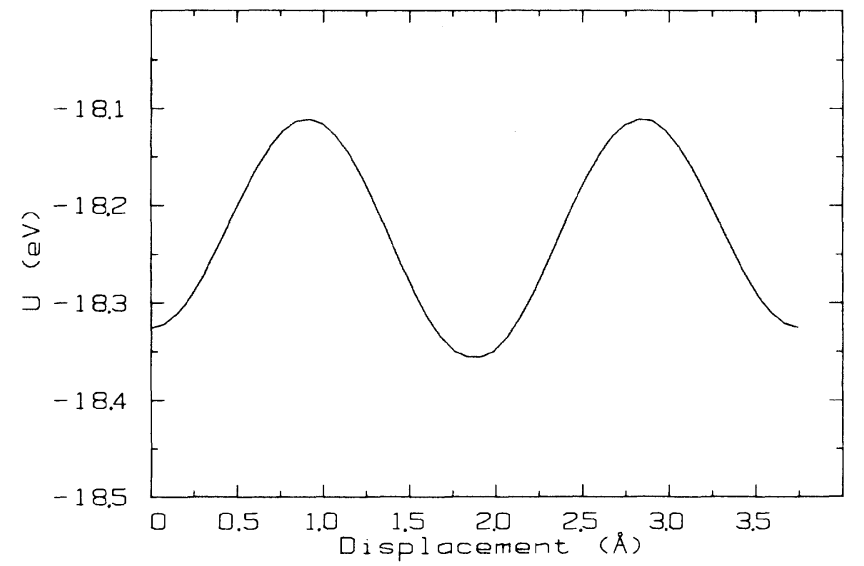

FIG. 5. Screened Coulomb potential energy of the $\mathrm{O}(1)$ ions as a function of displacement in the $a$ direction.

double well could provide the electron-phonon coupling enhancement required suggested by the modified Eliashberg theory of Hardy and Flocken. ${ }^{17}$

Neutron scattering data ${ }^{18}$ show that either the thermal average positions of the $O(1)$ ions are greatly elongated in the $a$ direction, or the ions actually sit on either side of the le symmetry site. This type of behavior would be expected if the $O(1)$ ions were moving in a double-well potential. There is also evidence that polycrystalline samples of $\mathrm{Y}$ $\mathrm{Ba}-\mathrm{Cu}-\mathrm{O}$ exhibit an anomalously large static dielectric constant. ${ }^{19}$ Again, this is consistent with the $\mathrm{O}(1)$ ions moving in a double-well potential.

\section{CONCLUSIONS}

In summary, we have shown theoretically, that the $\mathrm{Y}$ $\mathrm{Ba}-\mathrm{Cu}-\mathrm{O}$ structure is inherently unstable within the limits of the rigid-ion model. We have further demonstrated that simple electronic screening is not sufficient to stabilize the lattice. On the basis of experimental data then, we postulate that this theoretical instability is manifested in the real crystal as a double-well potential, spanning the $1 e$ symmetry sites and elongated in the $a$ direction. The existence of this double-well potential would be consistent with and help explain several experimental phenomena. Further, the double-well potential is not only consistent with, but is necessary to one theory of the high $T_{c}$ seen in this compound.

\section{ACKNOWLEDGMENT}

This work was supported by the U. S. Office of Naval Research.
${ }^{1}$ J. G. Bednorz and K. A. Müller, Z. Phys. B 64, 189 (1986).

${ }^{2}$ M. K. Wu et al., Phys. Rev. Lett. 58, 908 (1987).

${ }^{3}$ T. Siegrist et al., Phys. Rev. B 35, 7137 (1987).

${ }^{4}$ M. Parrinello and A. Rahman, Phys. Rev. Lett. 45, 1196 (1980).
${ }^{5}$ R. G. Gordon and Y. S. Kim, J. Chem. Phys. 56, 3122 (1972).

${ }^{6}$ E. Clementi and C. Roetti, At. Data Nucl. Data Tables 14, 177 (1974).

${ }^{7}$ D. A. Liberman, D. T. Cromer, and J. T. Waber, Comput. Phys. Commun. 2, 102 (1971). 
${ }^{8}$ L. L. Boyer and J. R. Hardy, Phys. Rev. B 24, 2577 (1981).

${ }^{9}$ L. L. Boyer, J. Phys. C 17, 1825 (1984).

${ }^{10}$ P. J. Edwardson, V. Katkanant, and J. R. Hardy, Phys. Rev. B 35, 8470 (1987).

${ }^{11}$ W. I. F. David et al., Nature 327, 310 (1987).

${ }^{12}$ Frank J. Adrian, Phys. Rev. B 37, 2326 (1988).

${ }^{13}$ Y. LePage et al., Phys. Rev. B 35, 7245 (1987).

${ }^{14}$ M. S. Hegde and P. Ganguly, Phys. Rev. B 38, 4557 (1988).
${ }^{15}$ Y. Dai, A. Manthiram, A. Campion, and J. B. Goodenough, Phys. Rev. B 38, 5091 (1988).

${ }^{16} \mathrm{~J}$. Heremans, D. T. Morelli, G. W. Smith, and S. C. Strite III, Phys. Rev. B 37, 1604 (1988).

${ }^{17}$ J. R. Hardy and J. W. Flocken, Phys. Rev. Lett. 60, 2191 (1988).

${ }^{18}$ M. Francois et al., Solid State Commun. 66, 1117 (1988).

${ }^{19}$ L. R. Testardi et al., Phys. Rev. B 37, 2324 (1988). 